\title{
DISCURSO CERVANTINO Y NOVELA HISTÓRICA ROMÁNTICA
}

No parece casual que cuanto más penetra la labor investigadora en el tejido de la obra cervantina, más se revele la pervivencia de ésta en la literatura occidental. Desde los continuadores e imitadores dieciochescos del Quijote hasta la novelística más reciente, la presencia de Cervantes en las letras hispanas y extranjeras no ha cesado, si bien los centros de interés no siempre han sido los mismos: crítica de costumbres, quijotismo, equilibrio entre lo fantástico y lo real, polifonía, metaficción, carácter de work in progress... '

La novela española en sus diversas manifestaciones tras el falso paréntesis del siglo XVIII -moral y educativa, sentimental, gótica, anticlerical...- coexiste en las primeras décadas del XIX con un fuerte aluvión de traducciones ${ }^{2}$. En su devenir como crea-

1 Vid. J. Álvarez Barrientos, La novela en el siglo XVIn, en R. de la Fuente (ed.), Historia de la literatura española. Barcelona, Júcar, 1991; G. B. PALACín, El "Quijote' en la literatura universal Madrid, Leira, 1965; H. LEVIN, "Cervantes, el quijotismo y la posteridadw, en J. B. Avalle-Arce y E. C. Riley (eds.), Suma Cervantina Madrid, Tamesis Books, 1973, pp. 377-396; VV. AA., «Estudios comparados e influencia de Cervantes en la literatura universalw, en Cervantes. Su obra y su mundo. Madrid, Edi-6, 1981, pp. 975 y ss.; A.L. BAQUERO, Cervantes y cuatro autores del siglo XIX (Alarcón, Pereda, Valera y Clarín). Murcia, Universidad, 1989; C. EsCUDERo, Cervantes y la narrativa de Francisco Ayala Murcia, Universidad, 1989; A. BASANTA, "Cervantes y el Quijote en algunas novelas españolas de nuestro tiempon, en Actas del I Coloquio Internacional de la Asociación de Cervantistas. Barcelona, Anthropos, 1990, pp. 35-51, entre otros.

2 Vid. G. ZeLuers, «Bibliography of the spanish historical novel during the First Half of the Nineteenth Century". The University of New Mexico Bulletin, vol. II, núm. 1, 1929, pp. 3-16 y La novela histórica en España 1828-1850. Nueva York, Instituto de las Españas, 1938; R. BROWN, La novela española, 1700-1850. Madrid, Dirección General de Archivos y Bibliotecas, 1953; J. Fernández MonTEsinOS, Introducción a una historia de la novela en España, en el siglo XXX. Valencia, Cas- 
ción original se acoge al género histórico popularizado por W. Scott, quien desde 1830 (La dama del lago, El pirata...) gozaba de un gran éxito en nuestro país. Claro está que ya en 1825 este autor podía leerse en castellano en libros impresos en Londres, Burdeos o Perpiñán ${ }^{3}$.

El asentamiento definitivo de la novela histórica romántica, que ideológicamente muestra las dos tendencias europeas -igualmente legítimas- liberal o progresista y conservadora, se produce con la Colección editada por Delgado (1833-1835), a la que contribuyó con gran interés Ramón López Soler. Participó en los trámites legales de aquélla y desde las páginas de El Europeo, del que era redactor en 1823, y El Vapor, que dirigía en 1833, propició encendidas defensas del autor escocés bajo cuyo magisterio la novela española podía recuperar un ilustre pasado histórico fundado en la religión y en la monarquía 4.

A esta Colección de Novelas históricas originales españolas, que se inicia con El primogénito de Alburquerque del propio López Soler, pertenecieron El Doncel de don Enrique el Doliente de Larra, Sancho Saldaña de Espronceda, Los expatriados o Zulema y Gazul de Estanislao de Cosca Vayo, El golpe en vago de García de Villalta y Ni Rey ni Roque de Escosura, entre otras.

Con todo, Rafael Húmara ya había publicado Ramiro, Conde de Lucena (1823); Cosca Vayo, La conquista de Valencia por el Cid (1830); López Soler, Los bandos de Castilla (1830); Escosura, El Conde de Candespina (1832); y en Londres, y en inglés, Trueba y Cossío probaba fortuna con Gómez Arias (1828); The Castilian (1829) y The Romance of History Spain (1830); y Valentín de Llanos con Don Esteban (1825) y Sandoval s.

La crítica literaria tardó tiempo en descubrir que el modelo scottiano, adoptado con cierta torpeza por nuestros primeros cul-

talia, 1966; J. I. FerReras, El triunfo del liberalismo y de la novela histórica (1830-1870). Madrid, Taurus, 1976; Catálogo de novelas y novelistas españoles del siglo XXX. Madrid, Cátedra, 1979 y La novela española en el siglo XIX (hasta 1868). Madrid, Taurus, 1987; I. Zavala, Ideología y politica en la novela española del siglo XIX. Salamanca, Anaya, 1971; J. M. GONZÁlez HeRRÁN, La prosa romántica. Larra. Madrid, Cincel, 1981.

3 Vid. J. Fernández Montesinos, op. cit.; J. I. Ferreras, Los origenes de la novela decimonónica (1800-1830). Madrid, Taurus, 1973, además de las ya citadas; R. MARraST, «Ediciones perpiñanesas de Walter Scott en castellano (1824-1826)», en VV. AA., Romanticismo 3-4. La narrativa romantica. Atti del IV Congresso sul romanticismo spagnolo e ispanoamericano. Génova, 1988, pp. 69.79.

4 Vid. R. MARRast, José de Espronceda y su tiempo. Barcelona, Crítica, 1989, pp. 348-347; A. Gonzalez Palencia, La censura gubernativa en España (1800-1833), II. Madrid, Tipografía de Archivos, 1935, pp. 355.356.

5 Vid. S. Garcin CastaReda, Valentín de Llanos (1795-1885) y los origenes de la novela histórica. Valladolid, Excma. Diputación Provincial, 1991. 
tivadores del género y con más desenvoltura en los años treinta y cuarenta del siglo pasado ${ }^{\circ}$, era perfectamente compatible con elementos cervantinos de diversa índole, asimilados de desigual manera por los diferentes autores ?.

El escritor escocés conocía el Quijote, al que se refiere algunas veces en sus novelas y prólogos, y obviamente no podía ser ajeno a la fuerte tradición cervantina dieciochesca que en Gran Bretaña protagonizaron Richardson, Fielding, Smollett o Sterne.

A. L. Baquero ha demostrado cómo es patente en los escritores románticos la presencia de "huellas y ecos cervantinos» que van desde la utilización de determinados enunciados característicos o fórmulas fijas hasta recuerdos de personajes o ciertas aventuras, lo cual supone una desigual recepción de los textos de Cervantes ${ }^{8}$. Esa presencia puede detectarse, también, en el propio discurso de la novela histórica española de la tercera y cuarta décadas del siglo XIX.

Se ha analizado con pormenor cómo Ivanhoe (1819) -la obra que más influyó en nuestras producciones-y otras de su autor proporcionaron a los creadores románticos una variada gama de recursos narrativos, auténticos motivos genéricos, relacionados con la acción. Fueron aprovechados para despertar interés en el lector, en el que suscitaban diferentes expectativas unidas estrechamente a la anagnórisis y a la peripecia. Así, las novelas españolas, como las del escocés, recurren a prendas de reconocimiento, disfraces, personajes creídos muertos $u$ otros -frecuentemente judios- que dan un bebedizo a sus víctimas, juicios de Dios, torneos o duelos, incendios... No es difícil descubrir algo de esto en Los bandos de Castilla (1830), La conquista de Valencia por el Cid (1830), El Doncel de don Enrique el Doliente (1834), Sancho Saldaña (1834), La heredera de Sangumi (1835), El golpe en vago (1835), Ni Rey ni Roque (1835), Doña Isabel de Solís

- Vid. P. Churchman y E. A. Peers, «A survey of the influence of Sir Walter Scott in Spain», Revue Hispanique, LV, 1922, pp. 227-310; E. A. PEERS, «Studies in the influence of Sir Walter Scott in Spainw, Revue Hispanique, LXVIII, 1926, pp. 351-382; G. ZELLerS, "Influence of Scott in Spain*, en Scott and Certain Spanish Historical Novels, The University of New Mexico Bulletin, núm. 2, 1929, pp. 323, e «Influencia de Walter Scott en Españaw, Revista de Filologia Española, XVIII, 19.31, pp. 149-162.

7 Vid. A. L. BAouero Escudero, "Cervantes y la novela histórica romántica», Anales cervantinos, XXIV, 1986, pp. 1986, pp. 179-192; I. ROMÁN GuTIÉRREZ, Historia interna de la novela española del siglo XrX. I. Sevilla, Alfar, 1988, pp. 127148 y «La organización enunciativa de la novela histórica», Discurso, núm. 2, 1* semestre de 1988, pp. 109-121.

A. L. BAQURRO, art. cit. 
(1837-1846), Cristianos y moriscos (1838), El Señor de Bembibre (1844), Doña Blanca de Navarra (1846)... 9

Evidentemente, son técnicas propias del romance destinadas a producir intriga jugando con la curiosidad del lector. No fueron ignoradas por Cervantes en el Quijote, muchas de las Novelas ejemplares o el Persiles, y al canónigo toledano le parecían elemento fundamental en el tipo de narración — «suspendiendo los ánimos»- que defendía $(\mathrm{I}, 47)^{10}$.

Claro está que en el Quijote, aunque se parodien aspectos claves de los romances caballerescos, también se aprovechan con el fin legítimo de favorecer una lectura grata y amena. Como en ellos, aparecen en el relato personajes desconocidos cuya identidad se aclara más adelante. Así ocurre, por ejemplo, en la segunda parte cuando el lector descubre que los Caballeros de los Espejos y de la Blanca Luna no son sino el bachiller Sansón Carrasco.

Esto, que es muy frecuente en la novela histórica, incluyendo a Scott, suele ir unido a procedimientos de agnición. En Los bandos de Castilla, el fantasma que Blanca y su doncella creen ver es Sor Brígida. En La conquista de Valencia por el Cid, el Caballero de Armiño es don Rodrigo, hijo de Sancho García, rey de Navarra. En Ni Rey ni Roque, el pastelero es don Sebastián de Portugal. Desconocidos resultan para el lector en Sancho Saldaña - una de las novelas con más elementos de suspense-, el personaje con que se inicia la narración (Usdrobal), el supuesto loco que se da golpes en el pecho y besa la tierra (Zacarías), la extraña que avisa del peligro a Leonor (Elvira), la figura blanca que pasea por las almenas del castillo (Zoraida)...

${ }^{9}$ R. López SOler, Los bandos de Castilla o El caballero del Cisne, en F. Buendia, Antologia de la novela histórica española (1830-1844). Madrid, Aguilar, 1963, pp. 39-217; E. DE C. VAYO, La conquista de Valencia por el Cid, en Idem pp. 224-320; M. J. DE LARRA, El Doncel de don Enrique el Doliente, edic. de J. L. Varela. Madrid, Cátedra, 1982; J. DE EsPRONCEDA, Sancho Saldaña o El castellano de Cuéllar, edic. de A. Antón Andrés. Madrid, Taurus, 1984; J. CoRTADa y SalA, La heredera de Sangumi, en F. Buendía..., pp. 1128-1278; J. GARcia DE Villalta, El golpe en vago, Idem pp. 889-1121; P. DE LA EscosURA, Ni Rey ni Roque, Idem, pp. 760-881; F. MARTINez DE LA ROSA, Doña Isabel de Solis, Reina de Granada, Idem, pp. 1287-1593; J. Estéranez CALDERÓN, Cristianos y moriscos, Idem, pp. 15991627; E. GIl y Carrasco, El Señor de Bembibre, edic. de J.-L. Picoche. Madrid, Castalia, 1986; F. NAvarro Vllloslada, Doña Blanca de Navarra Madrid, Santa Coloma, 1846. Por estas ediciones se citará en adelante.

10 M. DE Cervantes, El ingenioso hidalgo don Quijote de la Mancha, edic. de L. A. Murillo - por la que en lo sucesivo se citará. Madrid, Castalia, 1987, p. 565. Vid, E. Moreno BAEZ, Reflexiones sobre el "Quijote". Madrid, Prensa Española, 1968; E. WILLunson, El "Quijote" y los libros de caballerias. Madrid, Taurus, 1991. 
Asimismo, en El Doncel de don Enrique el Doliente la misteriosa mano que logra detener a Macías en su duelo con Vadillo es la de Hernando, y el espíritu de la mora Zelindaja que habita en el castillo de Arjonilla es María de Albornoz. En Doña Blanca de Navarra, la hermosa labradora que se describe en el inicio de la novela es la princesa de Viana, y el desconocido que vence a Sancho de Rota, Gimeno.

En Cristianos y moriscos, de Estébanez Calderón y en Doña Isabel de Solis, de Martínez de la Rosa - ambas con pocos recursos de sorpresa pues el suspense se destruye en seguida, al contrario de las novelas de Espronceda y Navarro Villosladael mendigo lisiado del comienzo de la primera es Cigarral y los protagonistas de un divertido coloquio en igual situación en la segunda son la dueña Mari-Pérez y el escudero.

Con profusión hallamos en el Quijote sonidos, ruidos, gritos, músicas, apariencias o formas percibidas por el oído o la vista, de origen extraño. Tal ocurre en la aventura de los batanes o con la comitiva mortuoria. Lo mismo sucede en la novela histórica romántica, a lo que se suelen unir motivos propios del romance gótico como puertas secretas, cadenas, prisiones, supuestos espectros, pasadizos..

Se oyen rumores, cánticos y ruidos, en El Doncel de don Enrique el Doliente, que corresponden a la ventana que cierra Enrique de Villena, a las trovas de Macías, al herido que cae al suelo y al caballo de Vadillo que regresa de la cacería. Peransúrez y Hernando se verán sorprendidos por una sombra. Cuando en la novela de Espronceda, Saldaña tiene a Leonor desmayada en sus brazos se oyen pasos que serán de Zoraida.

La música cuyo sonido llega a don Lope, en Cristianos y moriscos, es ejecutada por María, y ella es la sombra blanca que salva el puente de un salto. También de blanca, además de negra, es calificada la sombra que se atraviesa en el camino, impidiendo la huida de Beatriz y don Alvaro en El Señor de Bembibre. Se trata del abad de Carracedo.

Pisadas de caballos y ruido de cascabeles se perciben en el capítulo VI -de reminiscencias cervantinas- de Doña Blanca de Navarra. Corresponden a las mulas adornadas con campanillas que arrastran una litera, en la que se esconde una monja que se descubrirá como la princesa de Viana.

Pero Cervantes no sólo con estos medios consigue la sorpresa, sino introduciendo elementos maravillosos, sobrenaturales o fantásticos, muy frecuentes en los libros de caballerías en los que la admiratio estaba asegurada, pues se dejaba volar sin trabas la imaginación. En este punto las ideas cervantinas no eran ab- 
solutamente originales. Como es bien conocido, el peso de la autoridad de Tasso y los neoaristotélicos italianos se deja notar entre nosotros, tras haber penetrado en España en la segunda mitad del siglo XVI a través de la impronta de Scaligero en las anotaciones de Herrera a Garcilaso y de forma sistemática por medio de la Filosofía antigua poética (1596), de López Pinciano ".

Cervantes, si bien limita en el terreno de la inventio las desmesuradas exageraciones del romance caballeresco buscando una acomodación o conformidad con el lector, también recorta los excesos de la veracidad histórica por la vía de la verdad poética. Esta síntesis que se resuelve en verosimilitud y probabilidad de la narración, es expresada por el canónigo en sus conocidas declaraciones programáticas del capítulo 47 de la primera parte:

\begin{abstract}
«Hanse de casar las fábulas mentirosas con el entendimiento de los que las leyeren, escribiéndose de suerte que, facilitando los imposibles, allanando las grandezas, suspendiendo los ánimos, admiren, suspendan, alborocen y entretengan, de modo que anden a un mismo paso la admiración y la alegría juntas; y todas estas cosas no podrá hacer el que huyere de la verisimilitud y de la imitación, en quien consiste la perfección de lo que se escribe» (p. 565).
\end{abstract}

Cervantes, aunque los medios fuesen paródicos, no renunció a provocar admiratio en el Quijote a través de aspectos fantásticos que el lector acepta al situarlos en la mente trastornada de Alonso Quijano.

W. Scott y los novelistas españoles introducen continuamente episodios de esta índole en sus narraciones. G. Carnero, siguiendo a Todorov, los considera aspectos de "lo maravilloso reductible a razóny ${ }^{12}$. Sin duda, y tal como llegó a declarar, el autor escocés no podía admitir los elementos sobrenaturales, espectros o monjas ensangrentadas tan abundantes en el romance gótico ${ }^{13}$. $\mathrm{Y}$ a tal falta de aprecio - parejo a la evolución del concepto de verosimilitud en el devenir del siglo- debía contribuir fuertemente sus propias reflexiones sobre el romance histórico. En términos parecidos a como Clara Reeve (The Progress of Romance, 1785) lo

$"$ Vid. E. C. RILEY, «Aspectos del concepto de admiratio en la teoría literaria del Siglo de Orow, en Homenaje a Dámaso Alonso, III. Madrid, Gredos, 1963, Teoria de la novela en Cervantes. Madrid, Taurus, 1971 y "Teoría literariaw, en J. B. Avalle Arce y E. C. Riley (eds.), Suma cervantina..., pp. 293-322; G. HALEY (ed.), El Quijote. Madrid, Taurus, 1980.

12 G. CARNRRO, «Apariciones, delirios, coincidencias. Actitudes ante lo maravilloso en la novela histórica española del segundo tercio del XIX, Insula núm. 318, mayo 1973, pp. 1 y 13-15.

i3 G. Carnero, art. cit., recoge un artículo de W. Scott (Revue de Paris, abril 1829) en el que disiente de estos aspectos inverosímiles. 
había hecho, distingue entre romance y novela (Essay on Romance, 1824). El primero se centra en «hechos maravillosos y desusados", la segunda en "incidentes de la vida y de las condiciones modernas de la sociedadn. Pero el romance histórico es verosímil, aunque existan ingredientes ficticios: los hechos sorprendentes "que sobrepasen los cauces de la vida ordinaria" son compatibles con la descripción de "los caracteres y sentimientos de muchos de los actores (...) con la mayor verosimilitud, con gran variedad de sombreado y de delineación" ${ }^{14}$.

Por tanto, el novelista escocés al igual que nuestros autores románticos desterrará de sus producciones todo aquello que revestido de fantasía pueda negar esa verosimilitud.

Si se tienen en cuenta determinadas opiniones sobre lo fantástico, esta dimensión exige dos condiciones necesarias que se refieren a la naturaleza del texto y a su recepción por parte del lector. La primera implica que lo narrado obligue a aquél a considerar ese mundo de acontecimientos extraños como real, de tal manera que se produzca una "vacilación" a la hora de ser explicado, ya natural, ya sobrenaturalmente. La segunda, que supone una selección entre varios modos o niveles de lectura, significa que el lector adopte una determinada actitud frente a ese texto: rechazar toda interpretación alegórica o simbólica ${ }^{15}$.

Lo fantástico es una manifestación de síntomas o signos que basculan entre la realidad y su ausencia porque aparece inserto o circunscrito por esa realidad, lo cual supone un cierto atentado, una ambigüedad contra sí misma que el lector percibe ${ }^{16}$.

Las novelas de Scott y de los autores españoles de la tercera y cuarta década del siglo pasado incluyen en sus narraciones episodios que pueden ser considerados fantásticos a tenor de lo que se viene diciendo. En todos ellos lo maravilloso (excepcional o sobrenatural) de los hechos y lo extraño (su repercusión en un receptor que no ha inventado o imaginado) funcionan al unísono.

En Los bandos de Castilla, en un escenario netamente romántico (noche oscura, tormenta, bosque y viento) Beatriz cuenta a su señora Blanca de Castromerín una historia de aparecidos que continúa en una capilla no menos tétrica (ruinosa, poblada de

14 W. Scort, kintroducción» a The Fortunes of Nigel (1822), en M. Allot, Los novelistas y la novela. Barcelona, Seix Barral, 1966, p. 67. También en el capitulo I de Waverley (1814) se distancia del género gótico y sentimental al bromear sobre el título de su novela.

15 Vid. T. TODOROV, Introducción a la literatura fantástica. Barcelona, Ediciones Buenos Aires, 1982, pp. 43-45.

16 Vid. I. BÉssiére, Le récit fantastique. Paris, Larrousse, 1974; H. Belevan, Teoria de lo fantóstico. Barcelona, Anagrama, 1976. 
aves que emiten espantosos graznidos, con una sepultura a la que se le mueve la losa). Inmóviles y despavoridas oyen a su espalda una voz desconocida que dice: «De la muerte!» (p. 76). Proviene de un fantasma al que ven ama y doncella por el reflejo de un relámpago. Es una figura pálida y descarnada, vestida de negro con tocas blancas en la cabeza.

La conquista de Valencia por el Cid se abre con un episodio fantástico, de inequívoco aire cervantino, en el que Rodrigo Díaz de Vivar acaba de quitarle la vida al Conde de Nájera. Ya de noche, el escudero Gil se acerca al cadáver y en ese instante por la parte derrumbada del anfiteatro de las ruinas de Sagunto aparece una colosal figura con ropaje rojo. Asustado al creerlo un vestiglo, Gil tropieza y cae sobre el muerto del que no puede desasirse porque su almilla es traspasada por la punta del peto del Conde. Acaba desmayándose por el agotamiento de sus propios gritos, que el Cid no oye por el ruido del mar, y por miedo. Vuelto en sí por su señor, ve de nuevo al fantasma y aquél descarga sobre su cabeza un fuerte porrazo que le deja en el suelo sin vida.

En El Doncel de don Enrique el Doliente, inmediatamente después que el narrador relata la leyenda de la mora Zelindaja según la cual su espíritu sigue vagando por el castillo de Arjonilla, Nuño dice a Peransúrez que estando próximo a él vio una luz y una sombra y oyó: «Esposo, esposo mío» (p. 345).

Los dos personajes deciden penetrar en el castillo y cuando al incrédulo Peransúrez se le acerca una sombra, cree estar delante de la encantada mora.

En circunstancias bastante parecidas a las de Los bandos de Castilla - noche, tormenta, tempestad..., ya mencionadas-, mientras un bandolero cuenta una historia tétrica, en Sancho Saldaña, los oyentes y él, gracias a la luz de un relámpago que entra en la cueva, ven un espantoso fantasma, vestido de negro, con una antorcha en la mano. De ojos encendidos, por su semblante lívido, brazos largos, secos y descarnados, les parece un cadáver.

Un milagro de María cura la ceguera y tullimiento de Cigarral, en Cristianos y moriscos. Ferrán y Juan, criados de la condesa en Doña Blanca de Navarra, discuten sobre unos bultos que el primero ve al final del pasadizo e identifica con las andanzas de una endemoniada bruja. Sin embargo, el más escéptico que cree que ésta se convierte todas las noches en murciélagos, acaba diciendo: "por aquí se han escurrido estos fantasmas" (p. 194).

En todos estos pasajes, y otros que podrían añadirse, la supuesta fantasía estrechamente relacionada con el suspense cede a interpretaciones absolutamente contrarias que, de hecho, acaban 
destruyéndola. Así, en la novela de López Soler el supuesto espectro de doña Jimena es Inés o Sor Brígida, a quien los remordimientos por la colaboración en el asesinato de la madre de Blanca, han trastornado. No hay tal vestiglo en la novela de Cosca Vayo, sino que es doña Sol, la hija del Cid, que habiendo sido raptadas por Abenxafa su madre y hermana, consigue huir vestida con la almalafa de un moro muerto y con la capucha de Fray Lázaro. Tampoco es el espíritu de la mora Zelindaja quien pervive en el castillo de Arjonilla, sino María de Albornoz a quien había encerrado allí su cruel marido Enrique de Villena. El fantasma de Sancho Saldaña es en realidad Elvira, la hermana desaparecida del protagonista. La supuesta curación milagrosa de Cigarral es fingida porque estaba completamente sano. En la novela de Navarro Villoslada, los dos bultos que los criados creen fantasmas corresponden a doña Blanca de Navarra y su amado Gimeno.

Esta fantasía, más tarde negada, que existe en la novela histórica romántica, debe ser relacionada con Cervantes. En el Quijote abundan este tipo de episodios, pero su condición de fantásticos se acaba diluyendo y es la verosimilitud quien resuelve el conflicto. Como en el texto cervantino, en las narraciones históricas una interpretación racional desmonta lo sobrenatural. Nunca se traspasa la barrera de lo verosímil y el posible desatino queda estéticamente justificado.

Cierta semejanza con las discutidas novelitas intercaladas del Quijote tienen las historias que algunos personajes relatan en las narraciones románticas. Si bien Cervantes pudo utilizarlas buscando la variedad que prescribía la poética renacentista, no por ello renunciaba, por la vía de la admiratio, a lo ameno de su lectura.

En Scott y los novelistas españoles favorecen el suspense e, incluso, son fuente de ironía porque con frecuencia son historias falsas o aparentemente verdaderas. En otras ocasiones, sin embargo, completan el argumento porque añaden datos desconocidos sobre los protagonistas. Por lo general tienen que ver con elementos del romance gótico ${ }^{17}$.

En Los bandos de Castilla, Beatriz relata a su señora cómo su antepasada Jimena que no correspondía al amor del duque Leopoldo, frecuentaba el bosque durante la noche hasta que un día no regresó más al castillo. Los sollozos de la misteriosa dama resuenan bajo la losa de una antigua sepultura que se encuentra

17 Vid. E. RuBio, «Novela histórica y folletín», Anales de la literatura española, núm. 1, Universidad de Alicante, 1982, pp. 269-281. 
en la capilla. También Inés, recogida por el padre de Blanca y última descendiente de Jimena, había desaparecido cuando su madre murió de una extraña dolencia.

Esta historia no sólo incrementa el suspense, sino que crea una atmósfera de terror al ser interrumpido su relato varias veces por la acción del viento, los truenos y el graznido de las aves nocturnas que pueblan la capilla. Algo muy semejante ocurre con la tétrica narración que hace, en Sancho Saldaña, el bandolero sobre el Señor de Rocafría que quería verse a solas con Lucifer. En ambos casos, las dos historias darán paso a la aparición de un espectro o fantasma, si bien la segunda es ajena e independiente del relato primero de la novela.

Para aclarar ciertos puntos sobre los personajes, algunos cuentan su vida como Usdrobal en el texto de Espronceda o Abén Alamín, en Doña Isabel de Solis, que narra la de Pedro Venegas, tío del joven cautivo por los moros. En la novela de Martínez de la Rosa - tan poco proclive a lo fantástico-, un mahometano relata las andanzas de la Princesa Encantada. Plagadas de elementos maravillosos, de lo que se ríen los asistentes, sirven para mostrar el carácter de aventura que tiene la estancia del joven Venegas en tierra de infieles y no añade nada al desarrollo de la acción. Lo contrario ocurre en Doña Blanca de Navarra donde el Marqués de Cortes cuenta cómo Alfonso de Nápoles, después de tener una hija bastarda con una dama humilde, se encuentra un día a ésta muerta, y no logra recuperar a la niña que supone desaparecida con su ama de leche. Avanzada la novela, continúa la historia la judía Raquel que revela el origen noble de Gimeno, tras confesar que había mentido en cuanto al sexo del vástago de don Alfonso.

Muy relacionado con la intriga, además de proporcionar algunos datos sobre la acción principal, está el manuscrito que Inés entrega a don Juan de Vargas en Ni Rey ni Roque. Como en El curioso impertinente, se interrumpe su lectura por la visita de Rodrigo de Santillana y el propio Vargas también lo hace para protestar, como don Quijote, de que alguien intente igualarse a su amada. El manuscrito contiene la vida de Clara, hermana de Inés, su matrimonio con un ilustre desconocido, su muerte en tierras francesas y la instalación en Madrigal de la propia Inés, su cuñado que ejerce de pastelero y su pequeña hija. No se indica, sin embargo, la identidad del marido de Clara.

De todas estas novelas, sólo en El Doncel de don Enrique el Doliente es el narrador quien cuenta una historia: la de mora Zelindaja. Es autónoma pero acaba incidiendo en el relato primero al ser asumida por los personajes que creen en la pervi- 
vencia de su espectro. Larra juega con la ironía pues la leyenda, de cuya falsedad advierte el propio narrador, parece encarnarse en el texto con ciertos visos reales que, finalmente, son destruidos: no hay tal espíritu de ultratumba, sino un ser de carne y hueso, María de Albornoz.

Resulta muy cervantino el que algunos personajes acomoden su conducta a determinadas lecturas. Elvira, en el Doncel larriano se identifica con Oriana y a Macías se le relaciona con Amadís. Por ser asidua lectora del famoso libro de caballerías, toma el amor cortés de sus protagonistas como un sentimiento idealizado que le sirve de modelo. En El Señor de Bembibre, la resignación cristiana de Beatriz ante la enfermedad y su desgracia amorosa es explicable porque las Sagradas Escrituras «desde que salió del monasterio era su libro más apreciado y que de continuo leía" (p. 317).

En otro orden de cosas, aunque en el Quijote se parodien los libros de caballerías también se teoriza sobre sus defectos y de manera muy especial sobre su dispositio. Cervantes tiene, para ello, muy presentes las ideas aristotélicas sobre la estructuración de los hechos y sobre la unidad de la fábula. El canónigo toledano critica los romances caballerescos porque los elementos no se enlazan:

\begin{abstract}
*No he visto ningún libro de caballerias que haga un cuerpo de fábula entero con todos sus miembros, de manera que el medio corresponda al principio, y el fin al principio y al medio; sino que los componen con tantos miembros, que más parece que llevan intención a formar una quimera o un monstruo que a hacer una figura proporcionada» (p. 565).
\end{abstract}

Los mismos "medios de enlace compositivo" que $\mathrm{H}$. Hatzfeld examinó en el texto cervantino ${ }^{18}$ son aplicados por W. Scott y nuestros creadores románticos. Resúmenes o recapitulaciones relacionan la composición que como tal romance tiene mucho de estructura episódica o sucesión de aventuras. Se refieren tanto a algo ya narrado como a algo no mencionado, pero sí sucedido. En frecuentes ocasiones el narrador utiliza fórmulas del tipo "como ya queda dicho", "ya hemos dicho", "según hemos dicho", "que ya se ha mencionado", entre otras.

Son abundantes también las transiciones que proporcionan cohesión a lo narrado:

${ }^{18}$ H. HATzFeld, El "Quijote" como obra de arte del lenguaje. Madrid, C.S.I.C., 1972, pp. 111-130. 
«Dejemos a don Enrique a la cabeza de los oficiales de su casa corriendo por el campo del Morow (El Doncel de don Enrique el Doliente, p. 153).

«Y estando en ella les dejamos meditando sus planes» (Sancho Saldaña, II, p. 195).

«Tiempo es ya que volvamos a doña Beatriz» (El Señor de Bembibre, p. 148).

«Volvamos ahora a la princesa de Viana» (Doña Blanca de Navarra, p. 238).

Cervantes, en su afán de combinar la unidad y la variedad, introdujo las novelitas - realmente romances - en el Quijote. Con la excepción de El curioso impertinente, las demás están relacionadas con mayor o menor fuerza con la acción principal y en ningún momento suponen un atentado contra esa unidad por más que se aluda a ello en el capítulo XIIV de la segunda parte ${ }^{19}$.

Las historias, ya mencionadas, que se narran en las novelas románticas gozan, por lo general, de idénticas prerrogativas ya que inciden, como antes se indicó, sobre el relato primero. Además, tanto Scott como los autores españoles se preocupan de dar gran coherencia a sus relatos al no dejar ningún cabo suelto y resolver cualquier circunstancia oscura.

Como se ha señalado con frecuencia, Cervantes practica en su inmortal libro una inusitada relación con el lector, que habría de hacerse patente en la novela decimonónica. Sin embargo, no es necesario avanzar hacia la segunda mitad del siglo porque tanto Scott como nuestros creadores retomaron esas intrusiones del narrador para condicionar al lector implícito. Son ingerencias que pretenden facilitarle cierta información, interpretan hechos o cuestiones relacionadas con algún personaje, muestran una evidente camaradería con ese lector, confían en su perspicacia y memoria, reconocen sus estados de ánimo -angustia, impaciencia, cansancio...-, o le advierten con ironía. Los ejemplos son innumerables.

Por este camino en que el narrador -siempre omnisciente en estos relatos- realiza funciones autoriales de tipo metanarrativo es fácil desembocar en el artificio cervantino de los cartapacios de Cide Hamete. Conocida es la finalidad paródica con que Cervantes sometió, a través del autor arábigo, al propio recurso uti-

${ }^{19}$ Allí se lee: «Y así, en esta segunda parte no quiso ingerir novelas sueltas ni pegadizas, sino algunos episodios que lo pareciesen, nacidos de los mesmos sucesos que la verdad ofrece (...) y pues se contiene y cierra en los estrechos límites de la narración, teniendo habilidad, suficiencia y entendimiento para tratar del universo todo, pide no se desprecie su trabajo, y se le den alabanza, no por lo que escribe, sino por lo que ha dejado de escribirn (pp. 366-367). 
lizado en los libros de caballerías para asegurar la veracidad que la narración estaba muy lejos de sugerir. Pero, en el Quijote, es también un subterfugio irónico si se observa el comportamiento del segundo autor con respecto a la historia de Cide Hamete y las opiniones de los tratadistas del momento sobre la objetividad que el uso de fuentes previas comunican a un relato. Calstelvetro, Picolomini o el Pinciano señalaban la importancia de narrar acontecimientos por boca de otros para proporcionarles imparcialidad. Sin embargo, el segundo autor del texto cervantino discrepa y enmienda, cuando le viene en gana, el manuscrito traducido por el morisco aljamiado.

Los escritores de los años treinta y cuarenta del siglo pasado que se acogen al género scottiano, recurren a un artificio similar al que el autor escocés puso en práctica en Ivanhoe, donde se alude al manuscrito de Sir Arthur Wardour, afín al autógrafo, manuscrito o cartapacio que se menciona en I promessi sposi (1833), de Manzoni. Este préstamo cervantino ${ }^{20}$, al que Scott renuncia en ocasiones, no fue utilizado siempre por nuestros escritores románticos, y cuando lo fue, es sorprendente el distanciamiento irónico a que es sometido, por lo que la huella del Quijote se hace todavía más evidente ${ }^{21}$. Claro está, sin embargo, que no lo hacen de igual forma, o de manera uniforme.

Es muy posible que la novela de Larra, El Doncel de don Enrique el Doliente, tan cervantina en varias facetas, sirviese de pauta en este aspecto a otras que vinieron después. Es llamativo que al contrario de lo esperable, se niegue la existencia de una fuente previa a la narración:

"debemos confesar que no hay crónica ni leyenda antiguas de donde la hayamos trabajosamente desenterrado; así que, el lector perdiera su tiempo si tratase de irle a buscar comprobantes en ningún libro antiguo ni modernow (p. 57).

Y esto contrasta con los shifters o marcas de historicidad del propio texto, que hacen referencia, sin embargo, a crónicas, cronistas, leyendas o historiadores del tiempo. Por otra parte el narrador, en función de autor implícito, se jacta de que la novela es más creíble que otras llamadas «historias verdaderas» (p. 57).

${ }^{20}$ Así lo considera J. L. Varela, ed. cit., p. 19, nota 4 bis. Vid. en directa relación con este artificio en el Quijote, S. LóPEZ NAVIA, El autor ficticio Cide Hamete Benengeli $y$ sus variantes $y$ pervivencia en las continuaciones $e$ imitaciones del "Quijote". Madrid, Universidad Complutense, 1990.

${ }^{21}$ No se emplea en: Ramiro, conde de Lucena, Los bandos de Castilla, La conquista de Valencia por el Cid, La heredera de Sangumi, Doña Isabel de Solis, Cristianos y moriscos, entre otras. 
Con estos juegos irónicos parece como si Larra estuviese parodiando las aspiraciones de veracidad, un tanto desmedidas, de algunos autores del género histórico ${ }^{22}$.

Al contrario que Larra, Espronceda en Sancho Saldaña utiliza una crónica. Pero el narrador, como en el Quijote, no sólo trasmite esa fuente, sino que la resume y compila («la crónica de la que copiamos, o por mejor decir extractamos, esta verdadera historia", II, p. 53, "pero como nuestro deber era compilar y no corregir, nos hemos conformado en todo con el originaln, II, p. 225).

Como el segundo autor cervantino, se juzga la crónica a la que se le achacan defectos, olvidos y algunas contradicciones (II, p. 253), y como a Cide Hamete, se le echa en cara al cronista que no entre en pormenores, que calle determinados nombres, que falsee ciertos datos (I, p. 88). Y, por supuesto, el narrador se exime de responsabilidades (II, p. 153).

También aquí se completa la historia con otras fuentes, halladas «a fuerza de escrutinios e investigaciones" (II, p. 255), que dan una información desconocida sobre algunos personajes que la crónica no contiene. Todo lo cual parece mantener la línea paródica impuesta por Larra en la Colección de Delgado.

En El golpe en vago, novela antijesuítica, García de Villalta recurre a un chusco vizcaíno que envía unos papeles a su editor. Se trata de la narración de las aventuras acaecidas a un marqués sevillano, del que era mayordomo el abuelo del vasco. Al igual en el Quijote, el autor marcado en el texto como Alejo Cavallastigardi y Chodepaturra, es tratado con la misma ironía con que Cervantes trata a Cide Hamete. Dice en su carta al editor que quiere hacerse rico con sus "cuentecitos" (p. 889), que debe cambiarse el nombre, delator de su origen ${ }^{23}$ y que como un crítico le ha aconsejado que no publique invenciones, se ha "guardado cual de pecar de poner una sola cosa sacada de mi cabeza» (p. 891). Con todo, la novela de García de Villalta está llena de lances que demuestran su adscripción al romance. $\mathrm{Y}$, por otra parte, si el narrador bromea en ocasiones sobre la omnisciencia (p. 901, por ejemplo), en otras parece abandonarla para transmitir con minuciosa exactitud un discurso teatral incluso con acota-

${ }^{22}$ I. ROMÁN (art. cit.) ha insistido en la faceta paródica de varios escritores. Vid. también, I. L. BERGoUIST, El narrador en la novela histórica española de la época romántica. University of California, Berkeley, Philadelphia, University Microfilms International, 1978.

${ }^{23}$ Con ello García de Villalta da muestras de su anticarlismo, en un momento en que, iniciada ya la primera guerra carlista, eran frecuentes las bromas sobre la facción vascongada - recuérdense los artículos de Larra. 
ciones. Esto ocurre en el diálogo entre el alcalde y el escribano que se inicia con: «He aquí el interrogatorio» (p. 391).

También en Ni Rey ni Roque se sigue manteniendo el recurso cervantino y scottiano de la fuente pretextual. Aquí, sin embargo, el autor se limita a transcribir unos legajos - la relación del marqués de Domiño- entregados por Sebastián de Vargas con la única condición de "variar algunos apellidos" (p. 764). No parece que su trabajo vaya más allá que el del amigo de Frank Osbaldiston, a quien éste da sus memorias, en Rob Roy (1817), del autor escocés.

De igual manera, Gil y Carrasco acude en El Señor de Bembibre al "manuscrito del que hemos sacado esta lamentable historia" (p. 412). No obstante, en ningún momento se advierten ironías que revelen manipulación o distanciamiento de esa fuente.

Como en Sancho Saldaña, se alude en la conclusión a otro documento complementador del manuscrito, ya que se da noticia de lo ocurrido a ciertos personajes. Se trata de uun códice antiguo escrito en latín" (p. 415) que, como los cartapacios de Cide Hamete, ha sido traducido "fielmente" (p. 415) por el narrador en su papel de autor implícito.

Resulta muy chocante, sin embargo, el tono festivo con que está escrita esta conclusión en evidente contraste con la seriedad del texto. Sirvan de ejemplo estas palabras: «En resumen, el tal manuscrito no parece sino un libro de defunciones; porque, según él hasta el mismo Mendo el palafrenero, fue víctima de una apoplejía fulminante que le trajo su obesidad, cada vez mayom (p. 413).

En Doña Blanca de Navarra, de Navarro Villoslada, son frecuentísimas las referencias a fuentes preexistentes, tales como crónicas, "coronista" (p. 17), cronicones, "algunos manuscritos de un fraile de Irache" (p. 17), el "manuscrito del fraile de Irache" (p. 80)... Sobre ellas se vierten continuas ironías y, aunque alguna vez, se advierta que simplemente se están transcribiendo (whemos copiadon, p. 65), no parece que la labor del narrador se limite a eso.

Este hace comentarios autoriales en los que muestra su decepción por no encontrar en la crónica el reflejo de los sentimientos de los protagonistas (p. 96), tan frecuente en las novelas del género; o critica el "referido cronicón" (p. 98) porque el fraile hace pesadas moralizaciones. Pero esto tiene más trascendencia de lo que parece ya que, como en el Quijote, el segundo autor manipula las fuentes previas. Por un lado, se expurgan pues esas moralizaciones no aparecen en el texto y, por otro, se amplían ya que se inserta una escena, en la que dialogan Gimeno y Gimena, que no existe en la crónica de Irache. Y así, se dice: 
«Pero sigamos el cuento, pues se nos antoja que los lectores han de tener más gusto en oir a los dos amantes, que a todos los coronistas del mundow (p. 98).

Por otra parte, al igual que se desconfía de Cide Hamete por su condición de moro, el testimonio del fraile no es fehaciente porque es supersticioso. Los raptores de doña Blanca le parecieron fantasmas, lo que atribuía a "artes de encantamento" (p. 17), y el propio autor dice que para explicar algunos "puntos históricos, persiste siempre en su teoría de los encantamentos" (p. 80); lo cual es cierto, si nos atenemos a sus manuscritos que se reproducen en un remedo de castellano antiguo (pp. 80-81).

Existe también en Doña Blanca de Navarra una burla de los posibles lectores eruditos que, sin duda, buscarían en el género de la novela histórica una exacta reproducción del pasado que, por desconocido, no podía realizarse. Mientras el narrador bromea sobre minucias que nada interesan para el desarrollo de los hechos y tacha de pesada una de las crónicas, comenta metanarrativamente:

«Fuera de que más de un erudito y anticuario, tomará notas acerca de este acontecimiento, e invocará nuestro testimonio en su disertación futura, sobre el modo de conducir a las damas descoloridas, cuando se desmayan en los salones" (pp. 135-136).

La novela de Navarro Villoslada en la que se halla un fuerte substrato cervantino -incluidos los títulos de los capítulos-, parece también seguir la línea paródica que Larra iniciaba en la Colección de Novelas históricas originales españolas. Sin embargo, la asimilación del Quijote es mucho más fina en Fígaro que en el autor navarro.

Estrechamente relacionado con la distorsión semántica que en el texto cervantino adquiere la palabra historia, y dejando a un lado el peso que pueda tener en el propio género, nuestros autores románticos acuden con frecuencia al mismo procedimiento. Así se suele encontrar "verdadera historia», "verídica historia», "puntual historia», "peregrina historia»...

No hay duda que todos estos aspectos irónicos, y en especial el tratamiento a que son sometidas las fuentes previas - manuscritos, autógrafos, crónicas o leyendas - restan credibilidad a los textos. Con ello nuestros escritores románticos parodian, al igual que Cervantes lo hace con su inclusión en los libros de caballerías, el género literario que cultivan. Por otra parte, se detecta como a partir de los años cuarenta del siglo XIX sus produc- 
ciones, progresivamente, pierden en elementos históricos y ganan en elementos de invención ${ }^{24}$.

No resulta fácil explicar las causas que llevan a los novelistas seguidores de W. Scott a seguir derroteros irónicos y paródicos. Es posible, sin embargo, relacionarlo con cuestiones que afectan a la poética del género.

Ciertamente la novela histórica encierra la paradoja de que en ella conviven aspectos de órdenes diferentes: lo ficticio y lo real ${ }^{25}$. Esta posible antinomia entre lo novelesco y lo histórico se salva acudiendo a la verdad poética de Aristóteles, para quien era "preferible lo imposible verosímil a lo verdadero increíble" ${ }^{26}$.

En efecto, como se indicó más arriba, la novela histórica nace en Scott como romance histórico verosímil. Se renuncia, pues, a la veracidad desde su propio origen, al igual que lo harán V. Hugo y Larra en el capítulo primero de El Doncel de don Enrique el Doliente ${ }^{27}$. Sin embargo, Manzoni llega a repudiar el género histórico por su contradicción interna y acaba cometiendo la, para A. Alonso, herejía de exigir la verdad tanto a lo verosímil como a lo histórico, convertir lo verosímil en algo cierto o históricamente probable ${ }^{28}$.

Lo cierto es que considerar la verdad como criterio definidor de un texto histórico frente a la falsedad propia del texto de ficción no deja de ser un criterio insuficiente. Si se tiene en cuenta que lo verosímil no es sólo que el destinatario crea que es verdad lo que lee, sino que produzca, como sostiene $R$. Barthes, un nadas.

24 J. I. FERreras lo subraya reiteradamente. Vid. sus obras arriba mencio-

25 Vid. A. DASPRE, "Le roman historique et l'histoirex, en VV. AA., Le roman historique. Revue d'histoire littéraire de la France, núms. 2-3, mars-juin 1975, pp. 235-244; J. Molinó, "Qu'est-ce que le roman historiquex, en Idem, pp. 195234. A. LISTA se refiere también a la coexistencia de hechos exactos y personajes reales, sobre los que puede documentarse el novelista, y aventuras e incidentes fingidos ( $\ltimes$ De la novela históricaw, Artículo I, en Ensayos literarios y críticos, I. Sevilla, Calvo-Rubio y Compañia, Editores, 1844, pp. 156-159).

${ }^{26}$ ARISTÓteles, Poética, ed. trilingüe de V. García Yebra. Madrid, Gredos, 1974, p. 223.

${ }_{27}$ V. Hugo llegaba a declarar: «je préfère la vérité morale à la vérité historique* ( Sir Walter Scott a propos de Quentin Durward, en Litterature et Philosophie mêllees, Oeuvres complètes. Paris, Nelson, s.d., p. 239. Y Larra escribía: «respondemos (...) de que si no hubiese sucedido, pudo suceder cuanto vamos a contarn (p. 57).

${ }_{28}$ A. MANzon, «Del Romanzo Storico e, in genere, de'componimenti misti di Storia e d'invenzionew, en Opere. Milano-Napoli, Riccardo Ricciardi editore, 1958, pp. 1055-1114; A. Alonso, Ensayo sobre la novela histórica. El modernismo en "La gloria de don Ramiro". Madrid, Gredos, 1984, p. 59. 
effét de réel ${ }^{29}$, la clave no estará en la veracidad, y sí en el valor de veridicción de lo escrito, que demanda un pacto entre autor y lector.

Manzoni pedía veracidad a las narraciones históricas, nuestros autores parodian esa exigencia. Se sitúan en el ámbito de lo verosímil, pero con sus ironías sobre los pretextos literarios, fuente de veridicción, atentan contra ésta.

Tal como se ha venido analizando, los novelistas históricos españoles de la tercera y cuarta década del siglo pasado tienen presente a Cervantes a la hora de escribir sus narraciones. Pues bien, por paradójico que resulte, al acudir al Quijote es muy posible que asestasen un duro golpe al propio género por incluir en sus textos elementos que contradecían su misma esencia.

ERmitas Penas

Universidad de Santiago de Compostela

${ }^{29}$ R. BArthes, «L'effet de réel», Communications, n. 11, pp. 84-89. Vid J. Lozano, El discurso histórico. Madrid, Alianza Editorial, 1987. 